\title{
Variations in extreme precipitation and relation to the Asia summer monsoon over the Qinling-Dabashan Mountains, China
}

\author{
Jun $\mathrm{Li}^{1,2,3, *}$, Yuandi Zhao ${ }^{4}$, Dan Yang ${ }^{5}$, and Javed Iqbal Tanoli ${ }^{6}$ \\ ${ }^{1}$ School of Civil Engineering, Sichuan University of Science \& Engineering, Zigong, Sichuan, China \\ ${ }^{2}$ Sichuan Province University Key Laboratory of Bridge Non-Destruction Detecting and Engineering Computing, Zigong, \\ Sichuan, China \\ ${ }^{3}$ Geomathematics Key Laboratory of Sichuan Province (Chengdu University of Technology), Chengdu, China \\ ${ }^{4}$ School of Civil Engineering,College of Engineering, Universiti Teknologi MARA, Shah Alam, Selangor, Malaysia \\ ${ }^{5}$ School of Land and Resource, China West Normal University, Nanchong, Sichuan, China \\ ${ }^{6}$ Department of Earth Sciences, COMSATS University Islamabad, Abbottabad campus, Pakistan
}

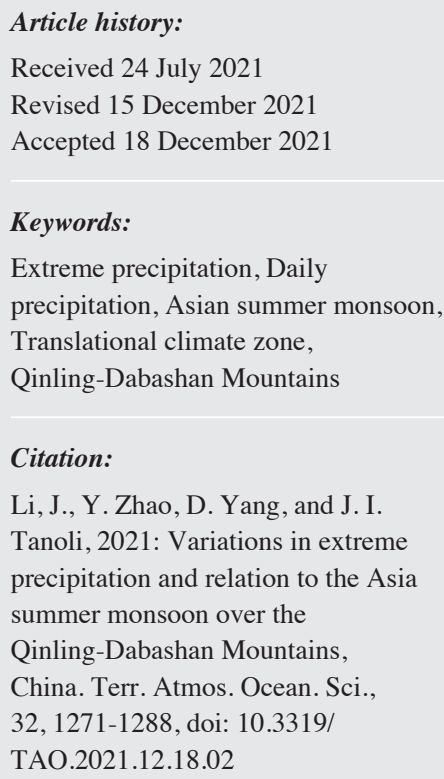

\begin{abstract}
The variations in extreme precipitation and their relation to large-scale climate circulation were investigated over a typical transitional climate zone named the Qinling-Dabashan Mountains from 1961 to 2018. In this study, the spatial and temporal variations in eleven extreme precipitation indices are determined using the Sen's method, Mann test and heuristic segmentation method. The relations between extreme precipitation and the Asia summer monsoon are analyzed by cross wavelet transform methods. The major findings of this research are as follows: (1) the spatial distribution of extreme precipitation changes over time in the Qinling-Dabashan Mountains: higher precipitation intensity occur in the middle and southeastern regions, while other regions exhibit adverse variation patterns. (2) Temporally, the regional trends of only the annual total wet day precipitation are dominant in the Qinling-Dabashan Mountains and its subregions. However, the regional trends of extreme precipitation are not statistically significant. In addition, the extreme precipitation in the Qinling-Dabashan Mountains and its subregions was sensitive to environmental changes from 1961 to 2018, including intensive human activity, the Asian summer monsoon and steep terrain. Sensitivity to environmental change implies flash floods and other natural disasters from 1961 to 2018. (3) The East Asian Summer Monsoon has a stronger influence than the South Asian Summer Monsoon on extreme precipitation. The results of this research will aid decision-makers in their response to recent climate change scenarios in the Qinling-Dabashan Mountains.
\end{abstract}

\section{INTRODUCTION}

Extreme precipitation events are a very rare type of precipitation but may lead to major impacts on natural and human systems. Under the background of global warming since the 1910s, many extreme precipitation events have caused many severe disasters worldwide (Sigdel and Ma 2017; Cui et al. 2019; Rahmani and Harrington 2019). For example, an extreme precipitation event occurred in Zhouqu County at 11:40 pm on $7^{\text {th }}$ August 2010, when the maximum hourly precipitation was $77.3 \mathrm{~mm}$, and a catastrophic debris flow resulted in 1557 deaths and 284 missing persons (Tang

\footnotetext{
* Corresponding author

E-mail: lijunxiaoyouxiang@163.com
}

et al. 2011; Wang et al. 2016).

In the context of strengthening the global response to the threat of climate change, studies on the changes in extreme precipitation and their relation to climate fluctuations have been widely conducted to evaluate the impact and risk levels of extreme precipitation (Zhang et al. 2018b). In China, Gao and Xie (2014) evaluated the trends in daily extreme precipitation and concluded that the positive trends of extreme precipitation are observed in some parts of the middle and lower reaches of the Yangtze River as well as in southeast China and parts of northwest China. Since the regional changes in extreme precipitation differ from one region to another, many regional studies have been carried 
out in various regions of China, including the Hengduan Mountains (Zhang et al. 2014a), southeastern Tibetan Plateau (Zhang et al. 2015), Chinese Loess Plateau (Sun et al. 2016), Yangtze River basin (Gao and Xie 2016), Yellow River basin (Zhang et al. 2014b), Wei River basin (Liu et al. 2017), Dongting Lake basin (Zhang and Liu 2016), central Himalayas (Sigdel and Ma 2017), and Sichuan Province (Li et al. 2019). The characteristics of extreme precipitation vary among regions due to differences in human activity, geography, geomorphology and climate circulation. However, there are few studies on the change in extreme precipitation and its relation to climate fluctuations in geographical and monsoonal transition zones, such as the Qinling-Dabashan Mountains (QDM) of China.

The QDM is a topographical transition zone between the Qinghai-Tibet Plateau and the eastern plain of China and a monsoonal transition zone of the Asian summer monsoon (ASM). For a long duration in the past, the QDM were given the name of the South-North transitional zone of climate, river and vegetation in China ( $\mathrm{Lu}$ and $\mathrm{Lu} 2019$ ). Studying the relationship between the extreme precipitation and the climate circulation in QDM is useful for predicting the extreme precipitation in other similarly transitional climate zones. Several scholars have preliminarily investigated the spatiotemporal variations in extreme precipitation using parts of extreme precipitation indices and analyzed the relation between extreme precipitation and ENSO events in the Qinling Mountains (Li 2014; Liu et al. 2017; $\mathrm{Lu}$ and $\mathrm{Lu}$ 2019). The results indicated a declining trend in rainy days and a positive trend in precipitation intensity along with an increase in the number of continuous drought events. In addition, extreme precipitation has a close relationship with ENSO events, and this region exhibits decreasing extreme precipitation in El Niño years ( $\mathrm{Li}$ et al. 2015a). However, the differences in the climatic variability in the QDM have not been fully explored, and the impact of the Asia summer monsoon (ASM), as a driver of precipitation anomalies (Wang et al. 2017), on extreme precipitation has not been fully discussed in the geographical and monsoonal translation zone. With these identified research gaps, the exact sensitivity of the QDM to climate change cannot be properly delineated.

The main story is shown as follows. Analysis of monthly, seasonal and annual extreme precipitation and the potential causes of variations by investigating the linkage between 11 extreme precipitation indices and Asian summer monsoon indices, could provide more details than previous studies, and be benefit for natural flood prevention and reduce economic losses over the QDM. In addressing the aforementioned issues, section 2 briefly describes the study area, data source, and section 3 is the methodology. Sections 4.1 and 4.2 introduce the spatial and temporal variations in extreme precipitation, respectively, using 11 indices recommended by the Expert Team on Climate Change
Detection and Indices (ETCCDI). Section 4.3 presents the impact of the South Asian summer monsoon (SASM) and the East Asian summer monsoon (EASM) on the duration, frequency and intensity of extreme precipitation. Section 5 discusses the influencing factors of extreme precipitation in the QDM. Section 6 presents the conclusions.

\section{STUDY AREA AND DATA}

According to the code of the China meteorological and geographic division, the QDM are divided into three meteorological regions, including the Qinling region, Dabashan region and Hanshui region (Fig. 1). The area of QDM is $31.04 \times 10^{4} \mathrm{~km}^{2}$. The QDM are at the western peaks of the Die Mountains and eastern peaks of the Shennongjia and Funiu Mountains. The QDM are a part of the zonal tectonic belt of the Qinling Mountains and the structural belt of the Dabashan Mountains. The annual precipitation ranges from 700 to $1300 \mathrm{~mm}$, and the regional precipitation is concentrated in the summer and autumn, which accounts for $70-80 \%$ of the precipitation of the entire year. The QDM fall within the second step of the Chinese mountainous system ranked on the basis of elevation drop, which is already described in the paper by Qi et al. (2017), from west to east. The terrain ascends from east to west in the Qinling region. The eastern Qinling region is bounded by high mountains and deep valleys, whereas the southeastern Qinling region has a canyon landscape topography. The landscape alternates between canyons and valleys in the Dabashan region. Most of the area in the Hanshui region comprises plains. According to the Chinese meteorological standards, 31 meteorological stations were selected to study the changes in extreme precipitation in the QDM. The basic information of the selected stations is shown in Fig. 1 and Table 1. The daily precipitation data for the selected stations were downloaded from the Chinese meteorological website (http://data.cma.cn/).

The data quality control procedures comprise two parts. First, the basic quality controls for all meteorological stations were completed by the China Meteorological Administration from March 2011 to June 2012. The missing data for each station is shown in Table 1. Most stations have a complete series of daily precipitation. The $0.5^{\circ} \times$ $0.5^{\circ}$ daily grid precipitation data were used to fill the missing data (Li 2014; Lu and Lu 2019). RClimdex V1 software was used to identify erroneous precipitation data and potential outliers during the first run, for example, precipitation values below $0 \mathrm{~mm}$. In this study, those outliers were manually validated or removed. Then, using a combination of the station metadata from the QDM and the penalized maximal F (PMF) test, RHtest V4 software was utilized to observe the multiple change points in the daily precipitation data series of all stations. The results reveal that only the Wudu station exhibited a change point, which occurred in April 1994 (Fig. 2). After checking the metadata for this 


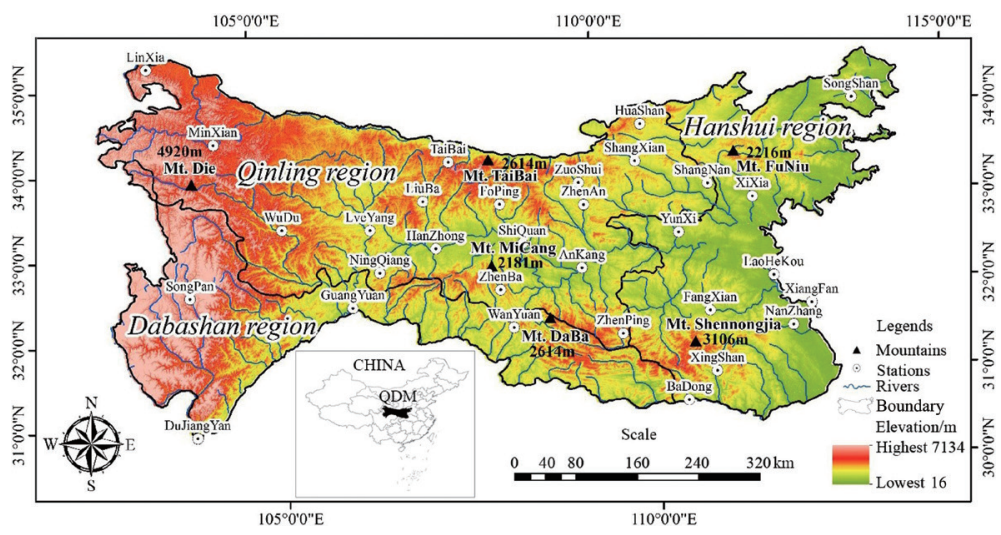

Fig. 1. The location of the QDM and the distribution of meteorological stations.

Table 1. Basic information of selected meteorological stations in the QDM.

\begin{tabular}{|c|c|c|c|c|c|c|}
\hline Regions & Station name & WMO number & North latitude & East longitude & Elevation (m) & Missing data \\
\hline \multirow{4}{*}{ Dabashan region } & Guangyuan & 57206 & 105.51 & 32.26 & 513.8 & $36 \mathrm{~d}$ \\
\hline & Songpan & 56182 & 103.36 & 32.4 & 2850.7 & None \\
\hline & Dujiangyan & 56188 & 103.4 & 31 & 698.5 & None \\
\hline & Wanyuan & 57237 & 108.02 & 32.04 & 674 & $1 \mathrm{~d}$ \\
\hline \multirow{9}{*}{ Hanshui region } & Badong & 57355 & 110.22 & 31.02 & 334 & None \\
\hline & Fangxian & 57259 & 110.45 & 32.03 & 426.9 & None \\
\hline & Laohekou & 57265 & 111.44 & 32.26 & 90 & $1 \mathrm{~d}$ \\
\hline & Nanzhang & 57363 & 111.5 & 31.48 & 151 & None \\
\hline & Xixia & 57156 & 111.3 & 33.18 & 151 & None \\
\hline & Xiangfan & 57278 & 112.05 & 32 & 68.6 & None \\
\hline & Xingshan & 57359 & 110.44 & 31.21 & 336.8 & None \\
\hline & Yunxi & 57251 & 110.25 & 33 & 249.1 & None \\
\hline & Songshan & 57084 & 113.03 & 34.3 & 1178.4 & $1 \mathrm{~d}$ \\
\hline \multirow{18}{*}{ Qinling region } & Ankang & 57245 & 109.02 & 32.43 & 290.8 & None \\
\hline & Foping & 57134 & 107.59 & 33.31 & 827.2 & None \\
\hline & Hanzhong & 57127 & 107.02 & 33.04 & 509.5 & None \\
\hline & Huashan & 57046 & 110.05 & 34.29 & 2064.9 & None \\
\hline & Linxia & 52984 & 103.11 & 35.35 & 1917.2 & None \\
\hline & Liuba & 57124 & 106.56 & 33.38 & 1032.1 & $1 \mathrm{~d}$ \\
\hline & Lueyang & 57106 & 106.09 & 33.19 & 794.2 & $3 \mathrm{~d}$ \\
\hline & Minxian & 56093 & 104.01 & 34.26 & 2315 & None \\
\hline & Ningqiang & 57211 & 106.15 & 32.5 & 836.1 & None \\
\hline & Shangnan & 57154 & 110.54 & 33.32 & 523 & $10 \mathrm{~d}$ \\
\hline & Shangxian & 57143 & 109.58 & 33.52 & 742.2 & None \\
\hline & Shiquan & 57232 & 108.16 & 33.03 & 484.9 & None \\
\hline & Taibai & 57028 & 107.19 & 34.02 & 1543.6 & None \\
\hline & Wudu & 56096 & 104.55 & 33.24 & 1079.1 & $10 \mathrm{~d}$ \\
\hline & Zhashui & 57140 & 109.07 & 33.4 & 818.2 & None \\
\hline & Zhenan & 57144 & 109.09 & 33.26 & 693.7 & None \\
\hline & Zhenba & 57238 & 107.54 & 32.32 & 693.9 & $1 \mathrm{~d}$ \\
\hline & Zhenping & 57343 & 109.32 & 31.54 & 995.8 & $1 \mathrm{~d}$ \\
\hline
\end{tabular}




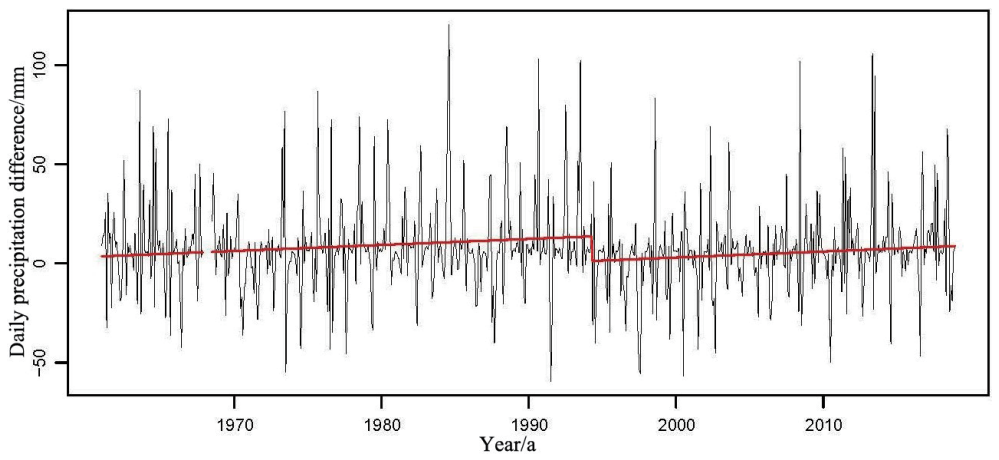

Fig. 2. Precipitation homogeneity assessment at the Wudu station.

station, no relocations or undated instruments occurred in that period. Based on the RX1day data checkup, it could be deduced that the change point might have been influenced by a rainstorm, suggesting that the change point at the Wudu station is not a true change. Therefore, all stations passed the homogeneity tests. The RClimdex V1 and RHtest V4 software were downloaded from the website of http://etccdi.pacificclimate.org/software.shtml (Wang 2008a, b). The trend changes in extreme precipitation are revealed by 11 extreme precipitation indices recommended by the World Meteorological Organization. In accordance with previous studies (Croitoru et al. 2013), those extreme precipitation indices are divided into precipitation days indices and precipitation indices. Table 2 represents the basic information on those extreme precipitation indices and the categories to which they belong.

\section{METHODOLOGY}

The methods for analyzing the changes in extreme precipitation and in relation to the ASM comprise four parts, and each method is described in detail. Firstly, the extreme precipitation indices are calculated with the RClimdex V1 software. Secondly, the trends of extreme precipitation indices are calculated with MAKESENS software with the method of Sen' method. The trend is considered to be statistically significant if it surpasses the 5\% level using the Mann test method. The Mann test also can be conducted in MAKESENS software (Salmi et al. 2002). Thirdly, the heuristic segmentation method was employed to reflect the characteristics of change points for precipitation on very wet days (R95) and precipitation on extremely wet days (R99) (Bernaola-Galván et al. 2001; Liu et al. 2017; Li et al. 2019). Fourthly, the relationships between the extreme precipitation indices and the ASM indices were analyzed by using the Cross Wavelet Transform (CWT) (Grinsted et al. 2004). The ASM indices comprise the South Asian summer monsoon index (SASMI) and East Asian summer monsoon index (EASMI); these data came from the Li Jianping research group, the readers can obtain the data from send a require email of ljp@lasg.iap.ac.cn or visit the website of http://www lijianping.cn, this email is open to the public ( $\mathrm{Li}$ and Zeng 2002; Li et al. 2010, 2012).

\subsection{RClimdex V1 Software}

The World Meteorological Organization put forward a set of extreme precipitation indices in the climate change monitoring conference from 1998 to 2001 (Karl et al. 1999; Peterson et al. 2001; Peterson 2005). The extreme precipitation indices became a unified standard for extreme precipitation change research. Among those extreme precipitation indices, the 11 indices of extreme precipitation are considered as the core indexes for extreme precipitation analysis in Table 2 . The 11 indices are calculated from daily precipitation data and have the characteristics of weak polarity, low noise and strong significance. However, the extreme precipitation indices are not easy to calculate, therefore, Xuebin Zang and Feng Yang developed and maintained a software named RClimDex V1 to easily and correctly calculate the 11 indices of extreme precipitation (Wang 2008a, b). After the extreme precipitation indices are calculated by the RClimDex V1, the correct of indices are manual checked.

\subsection{Sen's Method and Mann Test Method}

If a trend can be assumed to be linear, Sen's method can be utilized to compute the trend slope (Gilbert 1988). The equation of Sen's method is shown in Eq. (1):

$$
f(t)=Q t+B
$$

where $Q$ is the slope (trend) of extreme precipitation indices, $B$ is the constant of extreme precipitation indices, $f(t)$ is the continuously monotonic function of time, and $t$ is the daily precipitation data series from 1961 to 2018 . Here, the calculated value of trend is small with unit of $\mathrm{mm} /$ days in precipitation indices or days/year in precipitation days indices, in order to analysis the trend variation more convenience, 
Table 2. Definition descriptions and Abbreviation of extreme precipitation indices.

\begin{tabular}{|c|c|c|c|}
\hline Category & Indices & Full name & Descriptions \\
\hline \multirow{5}{*}{$\begin{array}{l}\text { Precipitation } \\
\text { day indices }\end{array}$} & $\begin{array}{c}\mathrm{R} 10 \\
\text { (days per decade) }\end{array}$ & Heavy precipitation days & Numbers of days when daily precipitation $\geq 10 \mathrm{~mm}$ \\
\hline & $\begin{array}{c}\mathrm{R} 20 \\
\text { (days per decade) }\end{array}$ & Very heavy precipitation days & Numbers of days when daily precipitation $\geq 20 \mathrm{~mm}$ \\
\hline & $\begin{array}{c}\mathrm{R} 25 \\
\text { (days per decade) }\end{array}$ & Extremely heavy precipitation days & Numbers of days when daily precipitation $\geq 25 \mathrm{~mm}$ \\
\hline & $\begin{array}{c}\text { CDD } \\
\text { (days per decade) }\end{array}$ & Consecutive dry days & $\begin{array}{l}\text { Maximum number of consecutive days when daily } \\
\text { precipitation }<1 \mathrm{~mm}\end{array}$ \\
\hline & $\begin{array}{c}\text { CWD } \\
\text { (days per decade) }\end{array}$ & Consecutive wet days & $\begin{array}{l}\text { Maximum number of consecutive days when daily } \\
\text { precipitation }>1 \mathrm{~mm}\end{array}$ \\
\hline \multirow{6}{*}{$\begin{array}{l}\text { Precipitation } \\
\quad \text { indices }\end{array}$} & $\begin{array}{c}\text { RX1day } \\
(\mathrm{mm} \text { per decade })\end{array}$ & Highest precipitation amount of one-day max & Annual maximum precipitation over 1-day intervals \\
\hline & $\begin{array}{l}\text { RX5day } \\
\text { (mm per decade) }\end{array}$ & $\begin{array}{l}\text { Highest precipitation of five-day max precipitation } \\
\text { amount }\end{array}$ & $\begin{array}{l}\text { Annual maximum precipitation sums over 5-day } \\
\text { intervals }\end{array}$ \\
\hline & $\begin{array}{c}\mathrm{R} 95 \\
(\mathrm{~mm} \text { per decade })\end{array}$ & Precipitation on very wet days & Annual total precipitation $>95$ th percentile \\
\hline & $\begin{array}{c}\text { R99 } \\
\text { (mm per decade) }\end{array}$ & Precipitation on extremely wet days & Annual total precipitation $>99$ th percentile \\
\hline & $\begin{array}{c}\text { SDII } \\
(\mathrm{mm} \text { per decade })\end{array}$ & Simple daily intensity index & $\begin{array}{l}\text { Annual total precipitation divided by the number of } \\
\text { wet days } \geq 1 \mathrm{~mm}\end{array}$ \\
\hline & $\begin{array}{c}\text { PRCPTOT } \\
\text { (mm per decade) }\end{array}$ & Annual total wet day precipitation & $\begin{array}{l}\text { Annual total precipitation from days with precipitation } \\
\qquad \geq 1 \mathrm{~mm}\end{array}$ \\
\hline
\end{tabular}

the calculated trend is multiplied by 10 , therefore, the unit of trend are $\mathrm{mm}$ per decade or days per decade.

To get the slope estimate $Q$ in Eq. (1), we first calculate the slopes of all data value pairs using the Eq. (2).

$Q_{i}=\operatorname{mean}\left(\frac{x_{j}-x_{k}}{j-k}\right), \forall j>i$

If there are $n$ values $x_{j}$ in the time series we get as many as $N$ $=n(n-1) / 2$ slope estimates $Q_{i}$. The Sen's estimator of slope is the median of these $N$ values of $Q_{i}$. The $N$ values of $Q_{i}$ are ranked from the smallest to the largest and the Sen's estimator is calculated by Eqs. (3) or (4).

$Q=Q_{[(N+1)] / 2}, \forall N$ is odd

$Q=\frac{1}{2}\left\{Q_{[(N / 2)]}+Q_{[(N+2)] / 2}\right\}, \forall N$ is even

The Mann test is applicable in cases when the data values $x_{i}$ of a time series can be assumed to obey the Eq. (5):

$x_{i}=f\left(t_{i}\right)+\varepsilon_{i}$

where $f\left(t_{i}\right)$ is a continuous monotonic increasing or decreasing function of time and the residuals $\varepsilon_{i}$ can be assumed to be from the same distribution with zero mean. It is therefore as- sumed that the variance of the distribution is constant in time.

For the Mann test, it is not essential that the data series obey distributions, and this test is not constrained by a few abnormal anomalies (Jaagus 2006). Therefore, we utilized this method to compute the significance of trends in extreme precipitation indices.

\subsection{Heuristic Segmentation Method}

At present, the research on extreme precipitation focuses on non-stationarity ( $\mathrm{Lu}$ and $\mathrm{Lu}$ 2019; Shao et al. 2019). Non-stationarity is mainly reflected that climate change and human activities change the temporal and spatial characteristics of precipitation, interfere the stationarity hypothesis of precipitation series, as a result, the extent of extreme precipitation was underestimate. In order to confirm the non-stationarity of extreme precipitation change, the heuristic segmentation method was used to detect the change points of the extreme precipitation indices in the QDM and three subregions. This method was introduced as follows to determine the mutation characteristics of extreme precipitation (Bernaola-Galván et al. 2001; Liu et al. 2017; Li et al. 2019). The difference in statistical significance $T(i)$ was calculated by Eq. (6). The Eq. (7) is used to calculate the $s(i)$ in Eq. (6). The largest difference in statistical significance $T$ can be obtained in a data series, which can represent the change point. We used Eq. (8) to compute and control the statistical significance $P\left(T_{\max }\right)$ corresponding to $T$. If the statistical significance is lower than the threshold 
of 0.95 , then the signal will not be divided into two parts; otherwise, the series be divided into two subsequences at that point. The iteration procedure continues recursively for each of the two subsequences until $P\left(T_{\max }\right) \leq 0.95$ or the length of the acquired segments is shorter than the minimum segment length $l_{0}\left(l_{0} \geq 25\right)$.

$$
\begin{aligned}
& T(i)=\left|\frac{\bar{x}_{1}-\bar{x}_{2}}{s(i)}\right| \\
& s(i)=\sqrt{\frac{\left(n_{1}-1\right) \times s_{1}+\left(n_{2}-1\right) \times s_{2}}{n_{1}+n_{2}-2} \times\left(\frac{1}{n_{1}}+\frac{1}{n_{2}}\right)} \\
& P\left(T_{\max }\right) \approx\left(1-I_{\left\{v /\left[v+\left(T_{\max }\right)^{2}\right]\right\}}(\delta v, \delta)\right)^{\eta}
\end{aligned}
$$

where $T(i)$ is the difference in statistical significance, $\bar{x}_{1}$ and $\bar{x}_{2}$ represent the left and right mean values, respectively, $s_{1}$ and $s_{2}$ represent the left and right standard deviations, respectively, $s(i)$ is the pooled variance, $n_{1}$ and $n_{2}$ are the length of the two side parts in a time series $n, P\left(T_{\max }\right)$ is the statistical significance, $I_{\left\{v /\left[v+\left(T_{\max }\right)^{2}\right\}\right\}}(\delta v, \delta)$ is the incomplete beta function, $\eta$ is equal to $4.19 \times \ln (n)-11.54$ based on the simulation of Monte Carlo, $v$ is equal to $n-2$, and $\delta$ is equal to 0.4 . Here, considering the time period of 58 years and the sensitive of threshold $P_{0}$, the minimum segment length $l_{0}$ was set to 40 , and the threshold $P_{0}$ was 0.95 .

\subsection{Cross Wavelet Transform}

The cross wavelet transform (CWT) and wavelet coherence can examine the relationships in time frequency space between two time series (Grinsted et al. 2004). Compared with the Fourier transform, the cross-wavelet transform (CWT) is more suitable to delineate the cross spectrum and oscillations of two time series (Jevrejeva et al. 2003; Grinsted et al. 2004; Huang et al. 2015). A software package of cross wavelet transform has been developed that allows users to perform the cross wavelet transform and wavelet coherence in the website of https://www.glaciology.net/publication/2004-12-24-application-of-the-crosswavelet-transform-and-wavelet-coherence-to-geophysicaltime-series/. Therefore, the relations between indices of extreme precipitation and the indices of ASM were analyzed by using the CWT.

\section{RESULTS}

\subsection{Spatial Change Characteristics of Extreme Precipitation}

\subsubsection{Precipitation Day Indices}

The spatial variations in the precipitation days indices are shown in Fig. 3. For consecutive dry days (CDDs), a slightly negative but statistically significant trend of -5.38 days per decade is shown at the Linxia station. The trends of CDD are ranged from -5.38 to 3.78 days per decade over the QDM. The positive trends are shown in the Qinling region, while the negative trends and no trends are shown in the Hanshui region and Dabashan region, and the significant change of CDD is detected in the western parts of QDM. For the consecutive wet days (CWD), no trends are observed in all stations except at the Minxian station and Dujiangyan station. The Minxian station has a significantly negative trend of -0.21 days per decade.

For the heavy precipitation days (R10), mostly negative or no trends are observed in the QDM, while only the middle of the eastern Qinling-Dabashan region has two slightly positive trends of 0.2 and 0.31 days per decade. The negative trends are changed from -1 to 0 days per decade, and the maximum negative trends of -1 day per decade are shown at the Huashan station. The trend at the Huashan station is statistically significant, it reveals the precipitation is occurred in the north Qinling Mountains, similar with the change of CWD.

For the very heavy precipitation days (R20), a large number of stations have no trends in the QDM. Only the Songpan station was statistically significant with a trend of 0.4 days per decade. Similarly, for the extremely heavy precipitation days (R25), most of the stations have no trends. Nine stations have slightly trends in the Qinling region, which range from -0.29 to 0.4 days per decade.

\section{1 .2 Precipitation Indices}

The spatial trend variations of precipitation indices are shown in Fig. 4. For the highest precipitation amount of a one-day maximum (RX1day), the positive trends ranging from 0.28 to $4.08 \mathrm{~mm}$ per decade are distributed in the western and southeastern parts of the QDM. Only the Shangxian station and Zhenping station have significantly positive trends of 3.16 and $4.08 \mathrm{~mm}$ per decade, respectively, it reveals the highest precipitation may be occurred in the middle of QDM. The middle and northeast regions have negative trends, which range from -0.18 to $-3.20 \mathrm{~mm}$ per decade.

For the highest precipitation of the maximum five-day precipitation amount (RX5day), positive trends are observed in the middle region of the Qinling-Dabashan Mountains, which range from 0.37 to $11.31 \mathrm{~mm}$ per decade. In addition, the western and eastern parts of the QDM have trends from -6.19 to $-0.19 \mathrm{~mm}$ per decade.

For precipitation on very wet days (R95), most eastern parts of the QDM have a positive trend except for a few parts in the northeastern region, and the values of positive trends range from 0.41 to $25.62 \mathrm{~mm}$ per decade. The western region has negative trends, which range from -8.16 to $-31.75 \mathrm{~mm}$ per decade. Only one station has significantly negative trends of $-25.37 \mathrm{~mm}$ per decade. 

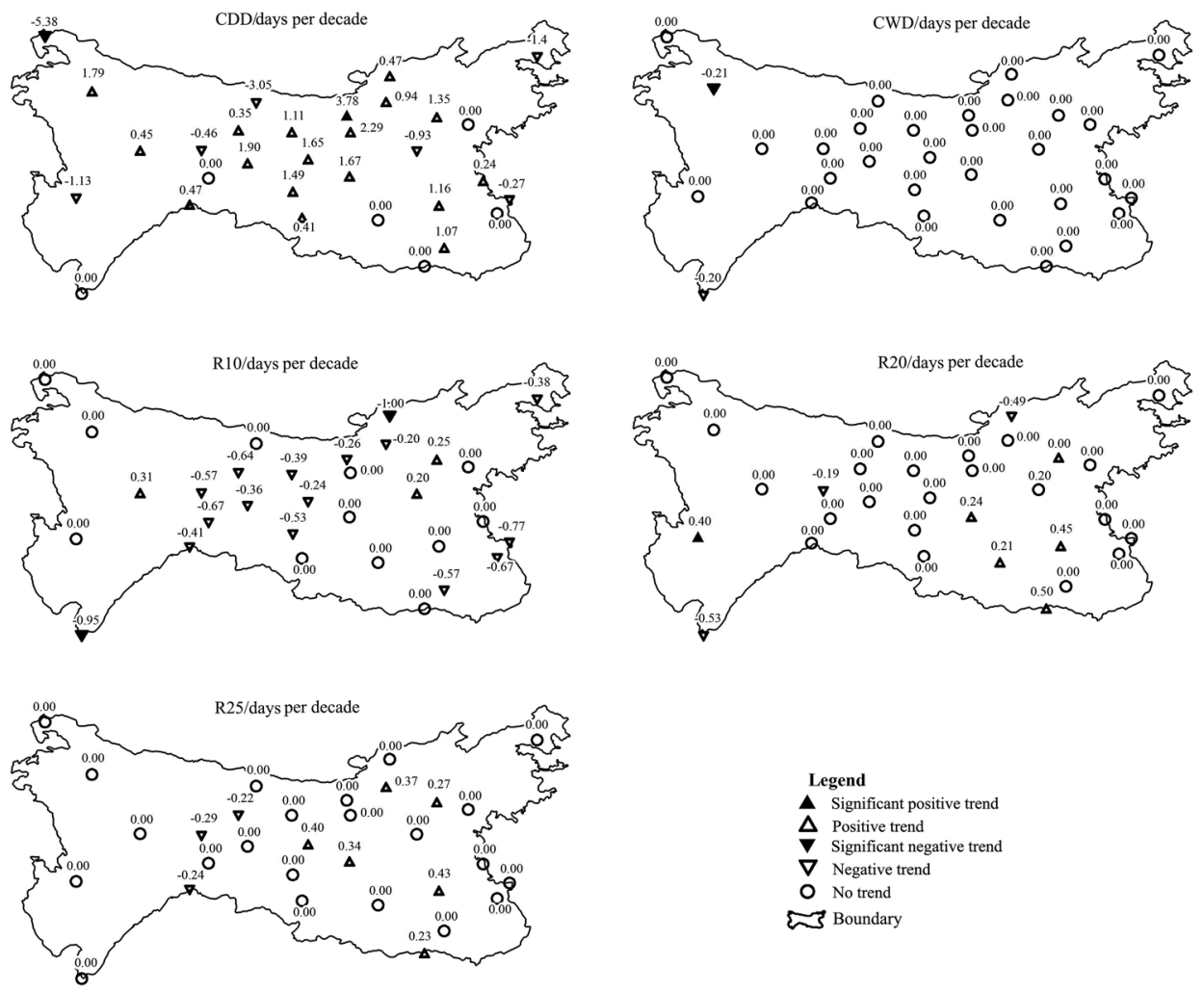

Fig. 3. Spatial distribution of trend changes in precipitation day indices from 1961 to 2018.
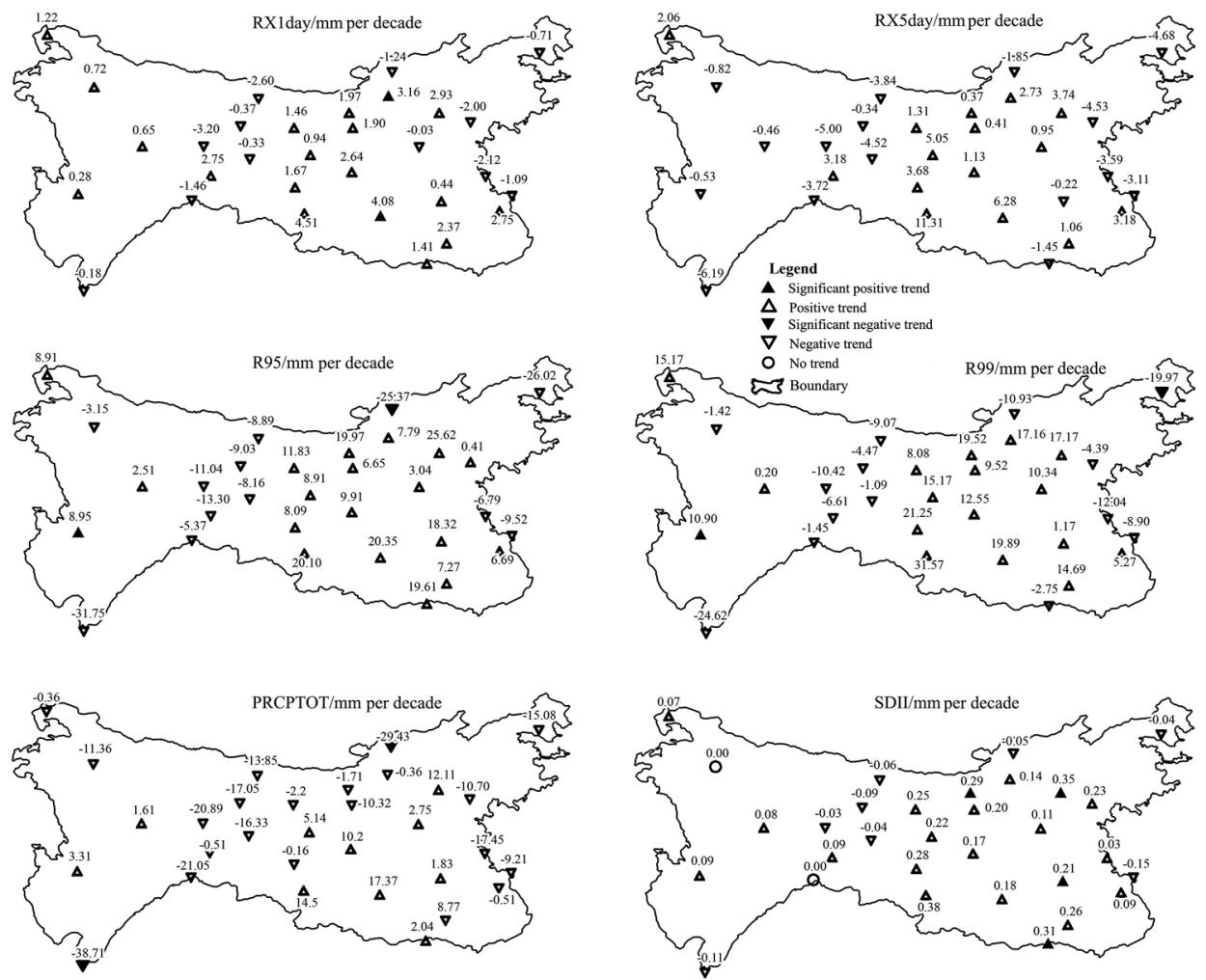

Fig. 4. Spatial distribution of trend changes in precipitation indices from 1961 to 2018. 
For precipitation on extremely wet days (R99), the southeastern part of the QDM shows a positive trend, ranging from 1.17 to $31.53 \mathrm{~mm}$ per decade. Only the Songshan station has a significantly negative trend of $-10.9 \mathrm{~mm}$ per decade. The western and northeastern parts of the QDM have negative trends, ranging from -1.42 to $-19.97 \mathrm{~mm}$ per decade.

For the simple daily intensity index (SDII), the east of the QDM has slightly positive trends. The value of positive or negative trends changed from -0.15 to $0.38 \mathrm{~mm}$ per decade. However, those trends are not statistically significant except the Fangxian station and Zuoshui.

For the annual total wet day precipitation (PRCPTOT), the QDM has negative trends except in the southeastern region. The values of negative trends change from -0.36 to $-38.71 \mathrm{~mm}$ per decade. Positive trends are observed in the southeastern region, which range from 0.24 to $14.19 \mathrm{~mm}$ per decade. The Huashan station and Dujiangyan station have a statistically significant trend of $-29.31 \mathrm{~mm}$ and -38.71 per decade, respectively. It reveals the obvious decreasing intensity change of PRCPTOT are occurred in the western and northeastern regions of the QDM.

\subsubsection{Brief Summary}

The spatial variations in extreme precipitation indices change slightly except for CDD, R95, R99, and PRCPTOT.
The middle and southeastern regions of the QDM have positive trends in CDD, while the western and northeastern regions of the QDM have negative trends in CDD. However, the spatial variations in R95, R99, and PRCPTOT have reverse trends in the QDM. Furthermore, the middle and southeastern regions have positive trends in all precipitation indices except SDII, while the western and northeastern regions of the QDM have negative trends. These results suggest that the middle and southeastern regions have abnormally large precipitation intensities, while the western and northeastern regions of the QDM depict adverse patterns.

\subsection{Temporal Change Characteristics of Extreme Precipitation}

\subsubsection{Precipitation Day Indices}

The regional trends of all precipitation day indices change slightly with time and show a nonsignificant status in the QDM (Fig. 5). Here, the regional trend of extreme precipitation indices is calculated from the average extreme precipitation indices of all stations by using the Sen's method. The CDD, R20, and R25 have slightly positive trends of $0.21,0.04$, and 0.08 days per decade, respectively. The trends of CWD and R10 are negative. The average CDD value is 43.59 days. The maximum CDD value (69.23 days) was detected in 1999 , and the minimum CDD value (25.26
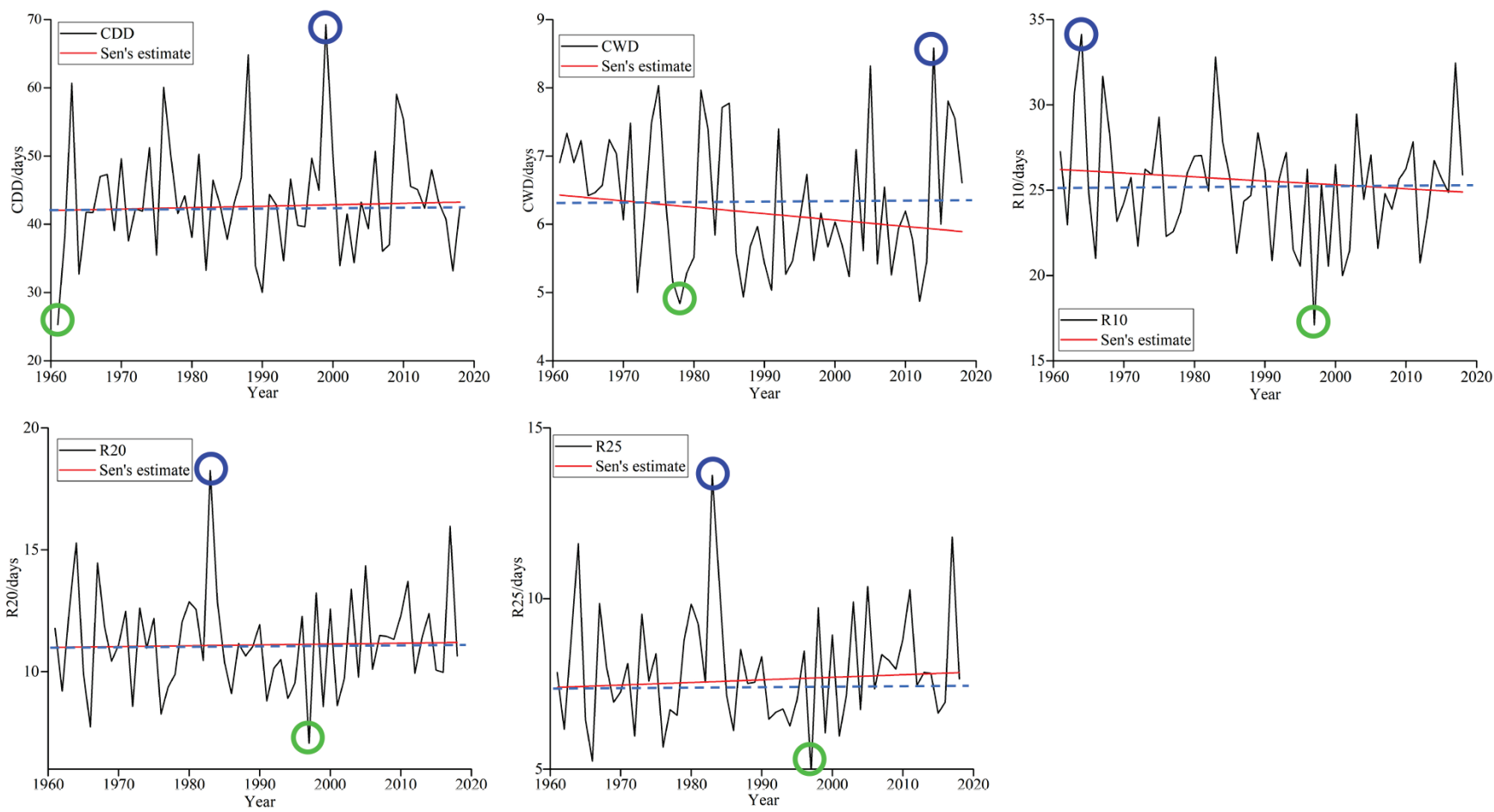

Fig. 5. Temporal changes in the trends of precipitation day indices. The black line is the series of indices from 1961 to 2017 . The red line is the slope of the linear trend for the indices. The blue circle indicates the occurrence point of the maximum value for the indices, the green circle indicates the occurrence point of the minimum value for the indices, and the blue dotted line indicates the average value for the indices. The trends of all indices are not pass the significant test of the $5 \%$ level. 
days) was observed in 1961. The maximum (8.58 days) and minimum (4.84 days) CWD values are shown in 2014 and 1978 , respectively, while the average values of R10, R20, and $\mathrm{R} 25$ are $25.27,11.21$, and 7.93 days, respectively. The minimum values of R10, R20, and R25 are all observed in 1961. Similarly, the maximum values of R20 and R25 are both observed in 1983. The maximum value of R10 is detected in 1964.

\subsubsection{Precipitation Indices}

The trends of precipitation indices are slightly positive except for the PRCPTOT index (Fig. 6). The regional negative trend of PRCPTOT is $-4.56 \mathrm{~mm}$ per decade. This result suggests that the amount of precipitation will decrease. The average values of PRCPTOT, R95, and R99 are 845.33, 532.3 , and $211.52 \mathrm{~mm}$, respectively. The average values of RX1day and RX5day are 72.94 and $122.94 \mathrm{~mm}$, respectively. The average value of SDII is $10 \mathrm{~mm}$, and this value is similar in other parts of China. The maximum values of RX1day and RX5day are both detected in 2010, and the maximum values of other precipitation indices are all observed in 1983. Moreover, the minimum values of RX1day and SDII are observed in 1976. Similarly, the minimum values of RX5day and R99 are observed in 1966, and the minimum values of R95 and PRCPTOT are observed in 1997.

\subsubsection{Regional Trend Differences in Three Subregions}

The analysis of decadal trends and the average values of the extreme precipitation indices for the three subregions are presented in Table 3. Only the PRCPTOT trends are negative in the three subregions. The negative trends of PRCPTOT are $-8,-6.49$, and $-3.69 \mathrm{~mm}$ per decade in the Dabashan region, Hanshui region, and Qinling region, respectively. The R99 index exhibits a positive trend of $4.01 \mathrm{~mm}$ per decade in the Qinling region, while the R99 index exhibits a negative trend of $-2.46 \mathrm{~mm}$ per decade in the Hanshui region. In addition, the trends of other extreme precipitation indices change slightly. The average values of RX1day, RX5day, R95, R99, PRCPTOT, and R10 all decrease in the order of the Dabashan region, Hanshui region, and Qinling region.

\subsubsection{Seasonal Change Characteristics of Extreme Precipitation Indices}

To detect the characteristics of the temporal changes in extreme precipitation, the seasonal changes in extreme precipitation indices on a regional scale (RX1day and RX5 day) are shown in Table 4 . The seasonal change processes of the average values for RX1day and RX5day are single peak waves, and the peak average values of 132.18 and
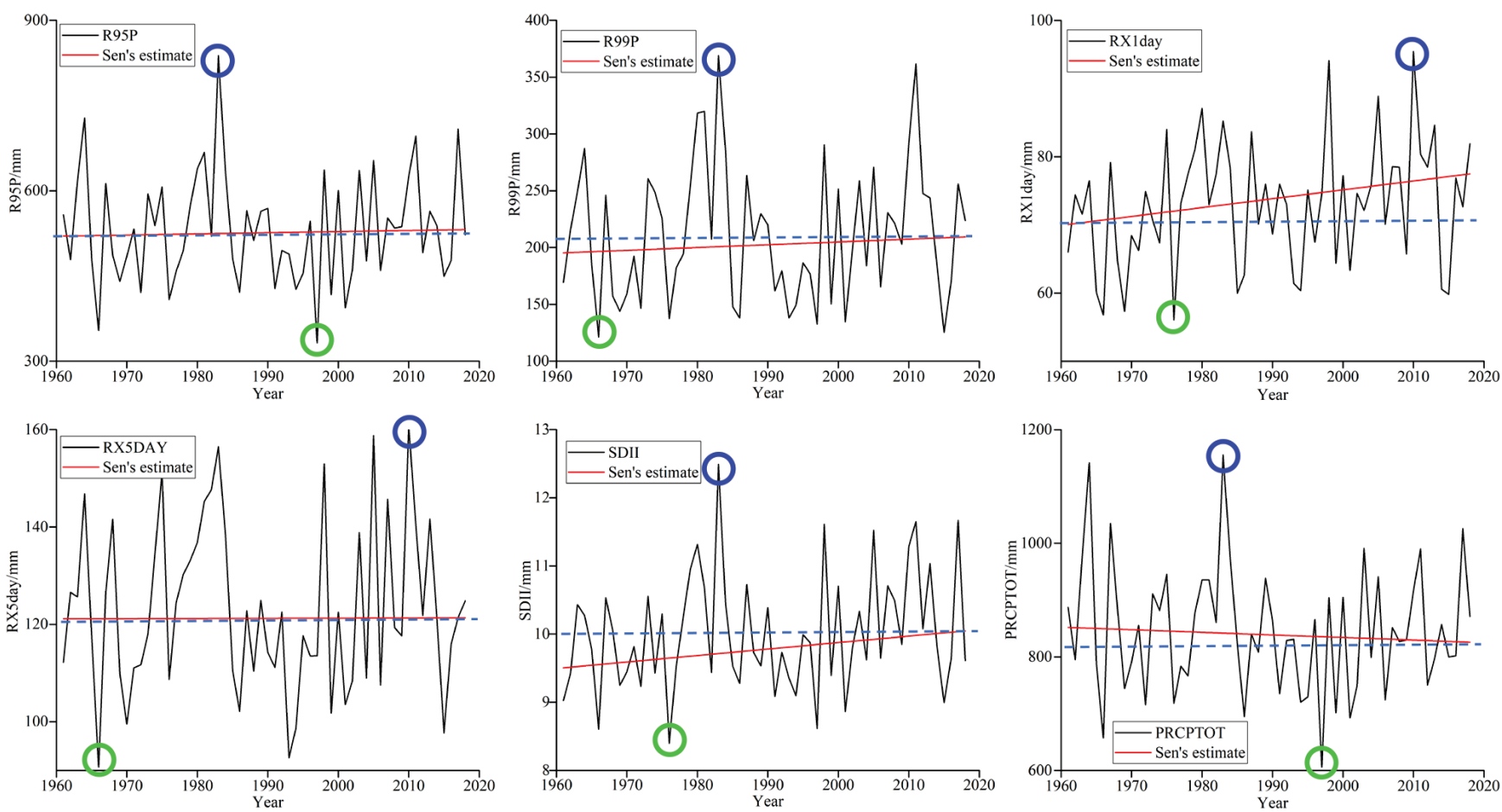

Fig. 6. Temporal changes in trends for precipitation indices. The black line is the series of indices from 1961 to 2017. The red line is the slope of the linear trend for indices. The blue circle indicates the occurrence point of the maximum value for the indices, the green circle indicates the occurrence point of the minimum value for the indices, and the blue dotted line indicates the average value for the indices. The trends of all indices are not pass the significant test of the $5 \%$ level. 
Table 3. Decadal trend rates and average value of extreme precipitation indices in the subregions.

\begin{tabular}{|c|c|c|c|c|c|c|}
\hline \multirow{2}{*}{ Indices } & \multicolumn{2}{|c|}{ Dabashan region } & \multicolumn{2}{|c|}{ Hanshui region } & \multicolumn{2}{|c|}{ Qinling region } \\
\hline & Average value & Trends & Average value & Trends & Average value & Trends \\
\hline $\begin{array}{c}\text { RX1day } \\
\text { (mm per decade) }\end{array}$ & 90.39 & 1.33 & 76.88 & 1.11 & 67.15 & 1.14 \\
\hline $\begin{array}{c}\text { RX5day } \\
\text { (mm per decade) }\end{array}$ & 158.31 & -0.02 & 121.71 & -0.77 & 115.66 & 0.29 \\
\hline $\begin{array}{c}\mathrm{R} 95 \\
\text { (mm per decade) }\end{array}$ & 615.47 & -0.26 & 557.49 & -0.54 & 501.68 & 2.95 \\
\hline $\begin{array}{c}\text { R99 } \\
\text { (mm per decade) }\end{array}$ & 261.86 & 0.30 & 216.45 & -2.46 & 198.02 & 4.01 \\
\hline $\begin{array}{c}\text { SDII } \\
\text { (mm per decade) }\end{array}$ & 10.33 & 0.07 & 10.67 & 0.08 & 9.62 & 0.10 \\
\hline $\begin{array}{c}\text { PRCPTOT } \\
\text { (mm per decade) }\end{array}$ & 1010.01 & -8.00 & 871.62 & -6.49 & 795.93 & -3.69 \\
\hline $\begin{array}{c}\text { CDD } \\
\text { (days per decade) } \\
\end{array}$ & 39.86 & 0.00 & 35.76 & 0.00 & 48.31 & 0.24 \\
\hline $\begin{array}{c}\text { CWD } \\
\text { (days per decade) }\end{array}$ & 7.33 & -0.13 & 6.01 & -0.11 & 6.26 & -0.07 \\
\hline $\begin{array}{c}\mathrm{R} 10 \\
\text { (days per decade) }\end{array}$ & 27.03 & -0.17 & 26.64 & -0.21 & 24.22 & -0.33 \\
\hline $\begin{array}{c}\mathrm{R} 20 \\
\text { (days per decade) }\end{array}$ & 12.10 & 0.00 & 12.29 & 0.09 & 10.48 & 0.02 \\
\hline $\begin{array}{c}\mathrm{R} 25 \\
\text { (days per decade) }\end{array}$ & 8.95 & 0.00 & 8.75 & 0.10 & 7.30 & 0.06 \\
\hline
\end{tabular}

Note: The value adding the symbol of "*” indicate that the trend coefficients passed the $95 \%$ statistically significant test.

Table 4. Regionally trend (mm per decade) of RX1day and RX5day in each season.

\begin{tabular}{c|cc|cc|cc|cc}
\hline \multirow{2}{*}{ Indices } & \multicolumn{2}{|c|}{ Spring } & \multicolumn{2}{c|}{ Summer } & \multicolumn{2}{c|}{ Autumn } & \multicolumn{2}{c}{ Winter } \\
\cline { 2 - 9 } & Average value & Trend & Average value & Trend & Average value & Trend & Average value & Trend \\
\hline RX1day & 63.88 & -0.04 & 132.18 & 1.89 & 71.96 & -1.23 & 14.42 & 0.01 \\
RX5day & 100.69 & -1.76 & 222.05 & 1.58 & 140.05 & -5.17 & 23.31 & -0.15 \\
\hline
\end{tabular}

Note: The value adding the symbol of “*” indicate that the trend coefficients passed the $95 \%$ statistically significant test.

$222.05 \mathrm{~mm}$ are observed during summer for RX1day and RX5day, respectively. The summer trends show increase individually at a rate of $1.89 \mathrm{~mm}$ per decade and $1.58 \mathrm{~mm}$ per decade in RX1day and RX5day. The spring and autumn trends of RX1day show slightly negative trends of -0.04 and $-1.23 \mathrm{~mm}$ per decade. The winter trend of RX1day is $0.01 \mathrm{~mm}$ per decade, suggesting a similar trend of winter values from 1961 to 2018. Moreover, the spring, autumn and winter trends of RX5day are negative. The autumn of RX5day has a negative trend of $-5.17 \mathrm{~mm}$ per decade from 1961 to 2018. However, the regional seasonal trends of RX1day and RX5day are statistically nonsignificant.

The seasonal changes in RX1day and RX5day are analyzed for the three subregions (Table 5). For spring and winter, the largest average values of RX1day and RX5day are observed in the Hanshui region. The Qinling region has the lowest average values of RX1day and RX5day. For sum- mer and autumn, the largest average values of RX1day and RX5day are observed in the Dabashan region. In addition, the Qinling region has the lowest average values of RX1day and RX5day. The trends of RX1day and RX5day in the Hanshui region mostly show slight decreases in all seasons, and only the spring of RX1day has a slightly positive trend of $0.33 \mathrm{~mm}$ per decade. The trends of RX1day and RX5day in the Dabashan region and Qinling region show slight increases or decreases across all seasons.

\subsubsection{Characteristics of Change Points in Extreme Precipitation}

The change points of extreme precipitation indices in the QDM and three subregions were detected by the heuristic segmentation method, as shown in Table 6. Before analyzing the characteristics of the change points, the 
Table 5. Decadal trend rates (mm per decade) and average value of precipitation indices in three subregions.

\begin{tabular}{c|l|cc|cc|cc}
\hline \multirow{2}{*}{ Seasons } & \multirow{2}{*}{ Indices } & \multicolumn{2}{|c|}{ Dabashan region } & \multicolumn{2}{c|}{ Hanshui region } & \multicolumn{2}{c}{ Qinling region } \\
\cline { 3 - 8 } & & Average value & Trend & Average value & Trend & Average value & Trend \\
\hline \multirow{2}{*}{ Spring } & RX1day & 63.15 & 0.75 & 74.12 & 0.33 & 58.93 & -0.49 \\
& RX5day & 103.07 & 0.29 & 116.10 & -2.45 & 92.46 & -2.09 \\
\hline \multirow{2}{*}{ Summer } & RX1day & 161.09 & -1.31 & 136.76 & -0.03 & 123.47 & 2.46 \\
& RX5day & 284.60 & 1.23 & 221.40 & -2.53 & 208.47 & 3.93 \\
\hline \multirow{2}{*}{ Autumn } & RX1day & 80.26 & 0.83 & 72.84 & -2.28 & 69.68 & -0.88 \\
& RX5day & 152.33 & -2.28 & 137.18 & -6.54 & 138.75 & -4.26 \\
\hline \multirow{2}{*}{ Winter } & RX1day & 13.06 & 0.47 & 21.67 & -0.46 & 11.09 & -0.02 \\
& RX5day & 18.46 & 0.50 & 36.93 & -0.78 & 17.58 & -0.04 \\
\hline
\end{tabular}

Note: The value adding the symbol of "*” indicate that the trend coefficients passed the $95 \%$ statistically significant test.

Table 6. The occurrence year of change points in the Qinling-Dabashan Mountains and three subregions.

\begin{tabular}{ccccc}
\hline Indices & Qinling-Dabashan Mountains & Dabashan Mountains & Hanshui Mountains & Qinling Mountains \\
\hline CDD & 1962201520082000 & 1989 & 1962200020082015 & 196220082016 \\
CWD & - & 1970 & - & - \\
R10 & 196519852016 & 1968200420122016 & - & 196919902016 \\
R20 & - & 196219852016 & - & - \\
R25 & - & 2016 & - & - \\
R95 & 1965201520092001 & 19932009 & 196219651967196820112016 & 2004 \\
R99 & 19731985 & 1963199920072008 & 1962196519671984 & 1978 \\
RX1DAY & 19771984 & 19792009 & 197220132017 & 1977 \\
RX5DAY & 1985 & 19842009 & 1962196519671984 & 1985 \\
SDII & - & - & - & - \\
PRCPTOT & 19651967196819852016 & 196519842016 & 19651967196820112016 & 1985 \\
\hline
\end{tabular}

segmentation processes were introduced by the representative indices of R99 in the QDM (Fig. 7). The first segmentation process of R99 is a solid line in Fig. 7, and a change point is observed in 1973 with $P\left(T_{\max }\right)=1>P_{0}$. The second segmentation process is a dotted line, and another change point is detected in 1985 .

No change points of SDII were detected in the QDM and three subregions. The change points occurred in all periods. The change points in the Dabashan Mountains are observed for all indices, such as the CDD in 1989, CWD in 1970, R10 in four random years, R20 in three random years, R25 in 2016, R95 in 1993 and 2009, R99 in four random years, RX1day in 1979 and 2009, RX5day in 1984 and 2009, and PRCPTOT in three random years. Therefore, the Dabashan Mountains experience obvious climate changes because all indices have change points except SDII. In addition, CDD, R95, R99, RX1day, RX5day, and PRCPTOT have change points in all regions. The change points of
R20, R25, and CWD are observed in only the Dabashan Mountains. R10 has change points in all regions except the Hanshui Mountains.

\subsubsection{Brief Summary}

The temporal change characteristics of extreme precipitation contain regional decadal trends, seasonal decadal trends, and change points in the QDM and three subregions. The regional trend of PRCPTOT shows a decrease at a rate of $10.24 \mathrm{~mm}$ per decade, while other extreme precipitation indices have slightly positive and negative regional trends in the QDM and its subregions. However, all extreme precipitation indices are not statistically significant. In addition, the seasonal trends of RX5day are slightly positive or negative in all seasons except autumn in the three subregions. Moreover, the extreme precipitation of the QDM and its subregions experienced several viable changes from 1961 to 2018. 


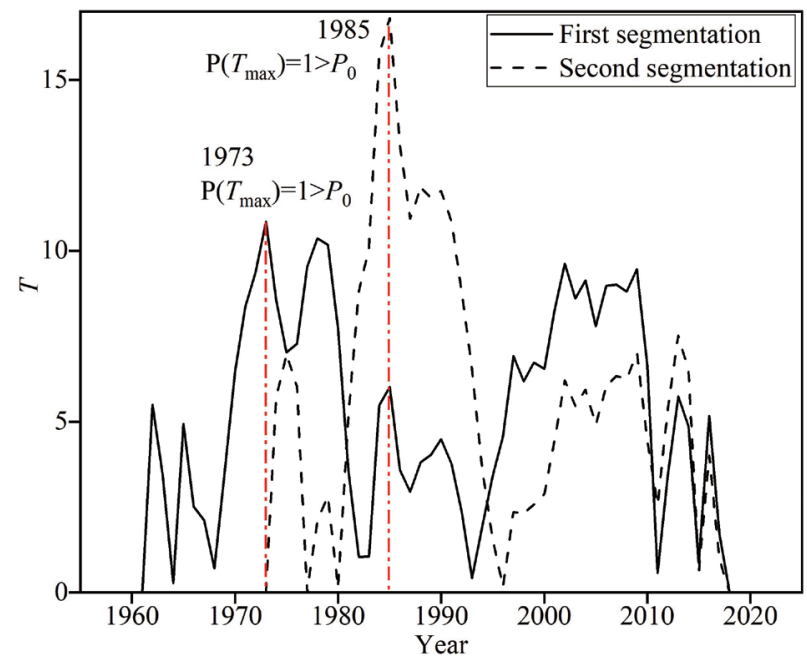

Fig. 7. The heuristic segmentation method detection for the non-stationary assumption of extreme precipitation change, representative segmentations and change points for R99 in the QDM, black solid line and black dotted line refer to the first and second iteration and segmentation process, respectively.

\subsection{Relationships Between the Extreme Precipitation Indices and the SASMI/EASMI During 1961 - 2018}

\subsubsection{Connection Between the SASMI and Extreme Precipitation Indices}

Figure 8a shows that RX1day has two statistically significant negative correlations with the SASMI at the $95 \%$ confidence level, within a signal of 2.5 - 4 years during $1965-1970$ and a signal of $1-2$ years during $1972-1978$. Figure 8 b shows that R95 has a statistically significant positive correlation with the SASMI, with a strong signal of 2 - 4 years during $1968-1972$. Figure $8 \mathrm{c}$ shows that the CWD has two statistically significant negative correlations with the SASMI, with a 1.5 -year oscillation signal during 1970 - 1972 and a signal of 2 - 4 years during 1993 - 1996. These results suggest that the changes in the intensity, frequency and duration of extreme precipitation are significantly linked to the SASMI regardless of whether positive or negative correlations exist in the QDM.

\subsubsection{Connection Between the EASM and Extreme Precipitation Indices}

In Fig. 9a, there are four statistically significant correlations between the EASM and RX1day, three are positive correlations with strong signals of 1 - 3 years during 1993 - 2000 and 2004 - 2010 and a strong signal of 4 - 5 years during 1982 - 1990, and the other is a negative correlation in the 8 - 10 years oscillation signal from 1984 to 1992. Figure 9b shows three statistically significant correlations between the EASM and RX1day. Two positive correlations include an obvious signal of 1 - 2 years during 1994 - 2000 and a signal of 8 - 12 years during 1974 - 1984. One negative correlation includes a strong signal of 2 - 5 years during 1981 - 1988 . Figure 9c shows that the EASM has four statistically significant positive correlations, with strong 2-5-year and 8-12-year signals during 1972 - 1988, a strong oscillation signal of 1.5 years during 2000 - 2002, and a strong oscillation signal of 3.5 years during 2008 - 2010. These statistically significant positive or negative correlations suggest that the changes in the intensity, frequency and duration of extreme precipitation are significantly linked to the EASM in the QDM.

\subsubsection{Brief Summary}

The QDM is a typical monsoon climate region, which is strongly influenced by the negative ASM (Ding et al. 2008). However, the detailed linkages between extreme precipitation and the SASM/EASM are not clear, and analyzing the evolution of this relationship is beneficial for predicting extreme precipitation events in the QDM. The relations between the SASMI/EASMI and RX1day/R95/CWD are analyzed by using the CWT method (Figs. 8 and 9). Here, RX1day, R95, and CWD represent the intensity, frequency and duration of extreme precipitation, respectively. The relations between the EASMI and RX1day/R95/CWD are stronger than the relations between the SASMI and RX1day/R95/CWD. This finding indicates that the intensity, frequency and duration of extreme precipitation in the QDM are more affected by the EASM than by the SASM.

\section{DISCUSSIONS}

The impacts of intense human activity, topography and water vapor sources on extreme precipitation are discussed in the following section. 

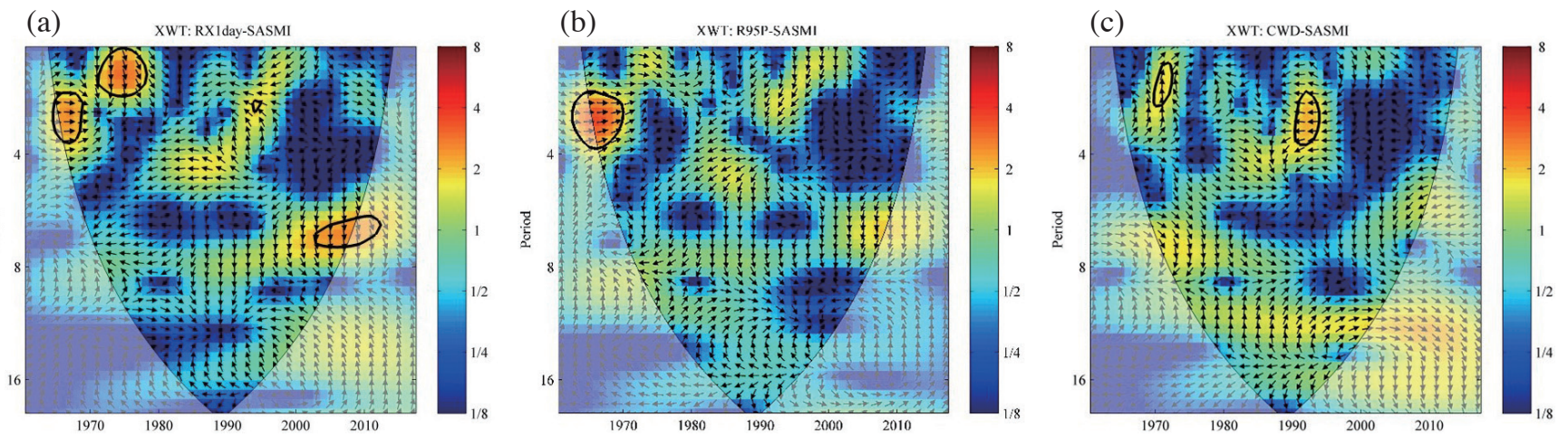

Fig. 8. The CWT spectra for (a) SASMI-RX1day, (b) SASMI-R95, and (c) SASMI-CWD in the QDM. Significant relations are denoted by a thick black contour, which is at the $5 \%$ level of significance. The light shades indicate the cone of influence. The relative phase relationship is shown as arrows (with in-phase pointing right, anti-phase pointing left, and RX1day/R95/CWD leading SASMI by $90^{\circ}$ pointing straight down, SASMI leading RX1day/R95/CWD by $90^{\circ}$ pointing straight up). Wavelet energy is expressed by the color bar on the right.

(a)

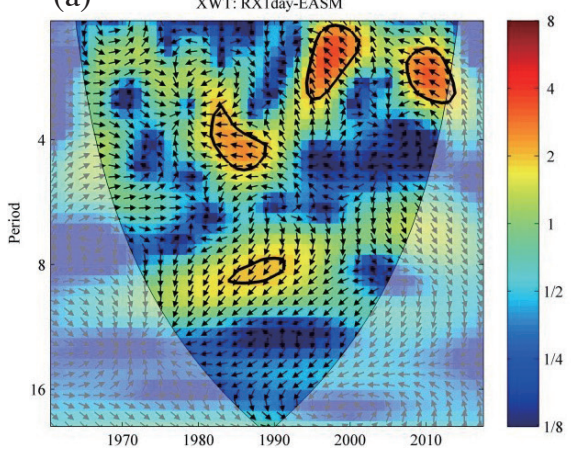

(b)

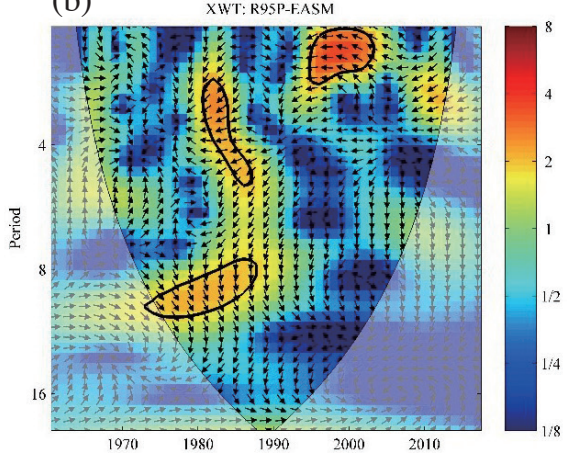

(c)

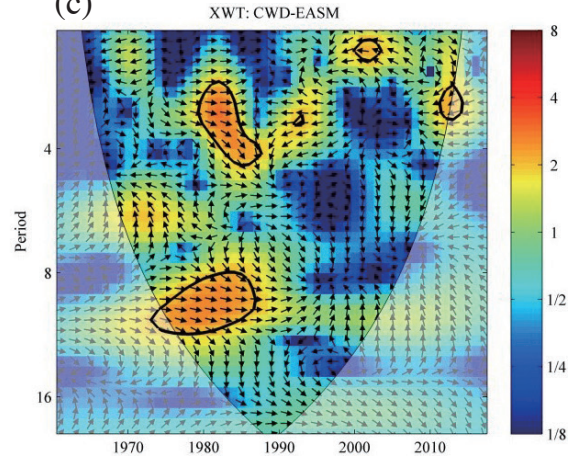

Fig. 9. The CWT spectra for (a) EASMI-RX1day, (b) EASMI-R95, and (c) EASMI-CWD in the QDM. Significant relations are denoted by a thick black contour, which is at the $5 \%$ level of significance. The light shades indicate the cone of influence. The light shades indicate the cone of influence. The relative phase relationship is shown as arrows (with in-phase pointing right, anti-phase pointing left, and RX1day/R95/CWD leading SASMI by $90^{\circ}$ pointing straight down, SASMI leading RX1day/R95/CWD by $90^{\circ}$ pointing straight up). The Wavelet energy is expressed by the color bar on the right.

The QDM is an area with rapid economic development in China with a population of 40 million. The GDP is 1585 billion RMB in 2019 according to the issuance of the Regional Development and Poverty Alleviation Plan for the QDM (http://www.ndrc.gov.cn). The land use change reveals the human activities (increased urbanization and unreasonable economic development) are increasing from 1961 to 2018 based on the NDVI map (Ren 2012; Bai 2020). From the spatial change of NDVI, the urbanizations and unreasonable economic developments are focused on the middle and southeastern regions in the QDM (Zhang et al. 2019). From the current research about the impact of land use change on the extreme precipitation, firstly, the urban processes and urbanization significantly influence the intensity and spatial distribution of precipitation (Goswami et al. 2010; Li et al. 2013; Yu and Liu 2015). Secondly, a hypothesis that the changes in urban land-use cause significant changes in extreme precipitation in urban centers and surrounding areas was test correctly in the focus places of
Mumbai, India and some urban in the China (Pathirana et al. 2014; Jin et al. 2015; Halder et al. 2016). The increased urbanization will lead to the lower latent heat flux (Zhang et al. 2019), which has reduced the total rainfall but increased the extreme precipitation event, moreover, our research results are consistent with this research, the average value of PRCPTOT decreased while the frequency of extreme precipitation raised in the QDM over the last 60 years. A region named Uttarakhand, India was used to research the impact of land-use changes on the genesis and evolution of extreme rainfall event using the Weather Research and Forecasting model (WRFV3.5). Their research shown the land use changes play an important role in the evolution and dynamics of the extreme precipitation events (Sahoo et al. 2020). This region is very similar with the middle and southeastern region of the QDM. Therefore, from the analysis, the intensive human activities may have a stronger relationship with the change of extreme precipitation in the QDM (Yu and Liu 2015). Therefore, it is reasonable that the intensive 
human activities may have stronger relationship with the change of extreme precipitation in the QDM.

The relationship between extreme precipitation and terrain are shown as follows. The winter cold wave sweeps from the Arctic Ocean in northwestern Russia to western Mongolia and finally reaches China. However, the cold air is blocked out of the Sichuan Basin throughout the year due to the barrier by the QDM. Therefore, extreme precipitation does not frequently occur in the QDM in winter. In addition, the topographic features of the QDM are such that the northern slope is abruptly steep, whereas the southern slope is gentle. This characteristic determines that the QDM have a strong blocking effect on the cold wave from the Arctic Ocean, while the warm and wet wave from the Asian summer monsoon can penetrate into the QDM. This phenomenon indicates that the effect of QDM topography have a stronger effect on the dynamic forced uplift and convergence of warm and humid air flow in summer monsoon, which lead the spatial distribution of extreme precipitation (Sun and Zhang 2017; Zhang et al. 2018a; Lu and Lu 2019).

The potential causes of variations between extreme precipitation and Asian summer monsoon are shown as follows. The water vapor supplies of precipitation mainly originate from the western Pacific Ocean, the Bay of Bengal and the South China Sea (Li and Zeng 2000; Wu 2002; Zhou and Lei 2018). Under the influence of the Pacific sub- tropical high, the ASM brings a large amount of water vapor from the western Pacific Ocean, Bay of Bengal and South China Sea (Wang et al. 2008). The variations of the location and direction of the Pacific subtropical high are well corroborated with the influences of the ASM on precipitation in China (Zhang et al. 2017; Zhong et al. 2017; Wang et al. 2021). Therefore, it is reasonable to illustrate the change of ASM may cause increased or decreased trend of extreme precipitation indices over QDM.

In addition, the comparison of the trends in different natural transition regions is meaningful to predict the extreme precipitation events in the QDM (Table 7). The QDM, Yunnan Province and Sichuan Province are influenced by the ASM. The regional trends in those zones slightly change for all indices except for PRCPTOT, R95, and R99. This result indicates that the regionally negative trends of precipitation intensity accompany the decreasing Asian summer monsoon (Ding et al. 2008). In addition, the central Himalayas are a topography and monsoon transitional zone. We compare the trends of extreme precipitation between the QDM and central Himalayas. The QDM and central Himalayas have slightly similar trends in most indices except PRCPTOT. Moreover, the PRCPTOT of the southern slopes of the Himalayas has a positive trend of 41 mm per decade, while the PRCPTOT of the northern slopes of the Himalayas has a slightly negative trend of $-3.7 \mathrm{~mm}$

Table 7. The decadal trends of extreme precipitation in the QDM and other transition zones in China.

\begin{tabular}{|c|c|c|c|c|c|}
\hline Indices & \begin{tabular}{|c|} 
QDM \\
$(1961-2018)$ \\
\end{tabular} & \begin{tabular}{|c|} 
Yunnan Province \\
$(1961$ - 2012)
\end{tabular} & \begin{tabular}{|c|}
$\begin{array}{c}\text { Sichuan Province } \\
(1961-2017)\end{array}$ \\
\end{tabular} & $\begin{array}{c}\text { The southern slopes of the central } \\
\text { Himalayas }(1975-2009)\end{array}$ & $\begin{array}{c}\text { The northern slopes of the central } \\
\text { Himalayas }(1975-2009)\end{array}$ \\
\hline $\begin{array}{c}\text { CDD } \\
\text { (days per decade) }\end{array}$ & 0.21 & 1.07 & 0.47 & 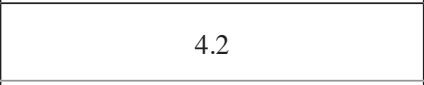 & 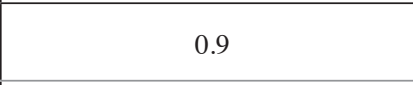 \\
\hline $\begin{array}{c}\text { CWD } \\
\text { (days per decade) } \\
\end{array}$ & -0.09 & $-0.37 *$ & -0.02 & $4.7^{*}$ & -0.4 \\
\hline $\begin{array}{c}\mathrm{R} 10 \\
\text { (days per decade) }\end{array}$ & -0.23 & -0.38 & 0.01 & 1.17 & -0.07 \\
\hline $\begin{array}{c}\text { R20 } \\
\text { (days per decade) } \\
\end{array}$ & 0.04 & - & 0 & 0.73 & -0.18 \\
\hline $\begin{array}{c}\mathrm{R} 25 \\
\text { (days per decade) }\end{array}$ & 0.08 & 0 & 0.01 & 0.6 & -0.1 \\
\hline $\begin{array}{c}\text { RX1day } \\
\text { (mm per decade) } \\
\end{array}$ & 1.3 & 0.4 & 0.26 & -1.7 & -1.5 \\
\hline $\begin{array}{c}\text { RX5day } \\
\text { (mm per decade) }\end{array}$ & 0.04 & -0.12 & 0.51 & 3.9 & -0.12 \\
\hline $\begin{array}{c}\mathrm{R} 95 \\
\text { (mm per decade) }\end{array}$ & 1.98 & 3.78 & 2.2 & 2 & -0.9 \\
\hline $\begin{array}{c}\text { R99 } \\
\text { (mm per decade) }\end{array}$ & 2.45 & 2.3 & 2.91 & - & - \\
\hline $\begin{array}{c}\text { SDII } \\
\text { (mm per decade) }\end{array}$ & 0.1 & 0.08 & 0.11 & -0.13 & 0.04 \\
\hline $\begin{array}{c}\text { PRCPTOT } \\
\text { (mm per decade) }\end{array}$ & -4.56 & -9.31 & 0.18 & 41 & -3.7 \\
\hline Data sources & This study & Li et al. $2015 b$ & Li et al. 2019 & \multicolumn{2}{|c|}{ Sigdel and Ma 2017} \\
\hline
\end{tabular}


per decade. Similarly, Sichuan Province is located in the southern mountain foot of the QDM (Zhou and Lei 2018), and the topographies of Sichuan Province and the QDM are similar to that on the southern and northern slopes of the central Himalayas. A negative trend of $-4.56 \mathrm{~mm}$ per decade is detected in the QDM. However, a positive trend of $0.18 \mathrm{~mm}$ per decade is observed in Sichuan Province. The adverse differences in PRCPTOT reveal that topography may be a key factor influencing the spatial variations in extreme precipitation (Prudhomme and Reed 1998; Sigdel and Ma 2017).

\section{CONCLUSIONS}

Spatially, the middle and southeast regions of the QDM have stronger precipitation intensity, while the other regions of the QDM have adverse pattern of extreme precipitation. Intense human activity, topographical changes and the ASM are the key factors influencing the abnormal variations in extreme precipitation in the QDM. Temporally, the regional trends of only PRCPTOT change larger in the QDM and three subregions. However, all regional trends of extreme precipitation indices are not statistically significant. The SASMI and EASMI can be an indicator to predict the extreme precipitation events in the QDM based on the strong relations between the intensity, duration and frequency of extreme precipitation and the SASMI/EASMI. In addition, we found that topographic differences and summer monsoons are two important factors influencing precipitation intensity due to the characteristics of the steep north and gentle south regions of the QDM. The decreasing ASM can penetrate into a large region of the QDM, while the cold waves from North Russia are blocked. In addition, the adverse regional trends of PRCPTOT occurred in the high altitudes of the QDM. The extent of the influence by the adverse regional trends of PRCPTOT may be determined by the West Asian Summer Monsoon. The extreme precipitation changes in the QDM are influenced by the decreasing strength of the ASM.

Acknowledgements Firstly, we thank the three anonymous reviewers for greatly improve the quality of this manuscript. Secondly, the authors gratefully thank the China Meteorological Administration for providing daily precipitation data in the QDM and gratefully thank the Li Jianping research group for providing the SASMI and EASMI data. The study was supported by Sichuan Science and Technology Program (Grant Nos. 2021 YFG0259), and supported by the opening project of Sichuan Province University Key Laboratory of Bridge Non-destruction Detecting and Engineering Computing (Grant Nos. 2020QZJ02), and supported by the talent introduction project of Sichuan University of Science \& Engineering (Grant Nos. 2018RCL09), and the opening fund of Geomathematics Key Laboratory of Sichuan Province (scsxdz2021yb08).

\section{REFERENCE}

Bai, Y., 2020: Development of the Spatio-temporal Variations Dataset of NDVI in Qinling-Daba Mountains of China (2000-2019). Journal of Global Change Data \& Discovery, 4, 346-353.

Bernaola-Galván, P., P. C. Ivanov, L. A. Nunes Amaral, and H. E. Stanley, 2001: Scale invariance in the nonstationarity of human heart rate. Phys. Rev. Lett., 87, 168105, doi: 10.1103/PhysRevLett.87.168105. [Link]

Croitoru, A.-E., B.-C. Chiotoroiu, V. Ivanova Todorova, and V. Torică, 2013: Changes in precipitation extremes on the Black Sea Western Coast. Glob. Planet. Change, 102, 10-19, doi: 10.1016/j.gloplacha.2013.01.004. [Link]

Cui, D., C. Wang, and J. Santisirisomboon, 2019: Characteristics of extreme precipitation over eastern Asia and its possible connections with Asian summer monsoon activity. Int. J. Climatol., 39, 711-723, doi: 10.1002/ joc.5837. [Link]

Ding, Y., Z. Wang, and Y. Sun, 2008: Inter-decadal variation of the summer precipitation in East China and its association with decreasing Asian summer monsoon. Part I: Observed evidences. Int. J. Climatol., 28, 11391161, doi: 10.1002/joc.1615. [Link]

Gao, T. and L. Xie, 2014: Study on Progress of the Trends and Physical causes of Extreme Precipitation in China During the Last 50 Years. Advances in Earth Science, 29, 577-589, doi: 10.11867/j.issn.10018166.2014.05.0577. [Link]

Gao, T. and L. Xie, 2016: Spatiotemporal changes in precipitation extremes over Yangtze River basin, China, considering the rainfall shift in the late 1970s. Glob. Planet. Change, 147, 106-124, doi: 10.1016/j.gloplacha.2016.10.016. [Link]

Gilbert, R. O., 1988: Statistical Methods for Environmental Pollution Monitoring. Biometrics, 44, 319, doi: 10.2307/2531935. [Link]

Goswami, P., H. Shivappa, and B. S. Goud, 2010: Impact of urbanization on tropical mesoscale events: Investigation of three heavy rainfall events. Meteorologische Zeitschrift, 19, 385-397, doi: 10.1127/09412948/2010/0468. [Link]

Grinsted, A., J. C. Moore, and S. Jevrejeva, 2004: Application of the cross wavelet transform and wavelet coherence to geophysical time series. Nonlinear Process Geophys., 11, 561-566, doi: 10.5194/npg-11-5612004. [Link]

Halder, S., S. K. Saha, P. A. Dirmeyer, T. N. Chase, and B. N. Goswami, 2016: Investigating the impact of land- 
use land-cover change on Indian summer monsoon daily rainfall and temperature during 1951-2005 using a regional climate model. Hydrol. Earth Syst. Sci., 20, 1765-1784, doi: 10.5194/hess-20-1765-2016. [Link]

Huang, S., Q. Huang, J. Chang, Y. Zhu, G. Leng, and L. Xing, 2015: Drought structure based on a nonparametric multivariate standardized drought index across the Yellow River basin, China. J. Hydrol., 530, 127-136, doi: 10.1016/j.jhydrol.2015.09.042. [Link]

Jaagus, J., 2006: Climatic changes in Estonia during the second half of the 20th century in relationship with changes in large-scale atmospheric circulation. Theor. Appl. Climatol., 83, 77-88, doi: 10.1007/s00704-0050161-0. [Link]

Jevrejeva, S., J. C. Moore, and A. Grinsted, 2003: Influence of the Arctic Oscillation and El Niño-Southern Oscillation (ENSO) on ice conditions in the Baltic Sea: The wavelet approach. J. Geophys. Res., 108, 4677, doi: 10.1029/2003JD003417. [Link]

Jin, M., Y. Li, and D. Su, 2015: Urban-induced mechanisms for an extreme rainfall event in Beijing China: A satellite perspective. Climate, 3, 193-209, doi: 10.3390/ cli3010193. [Link]

Karl, T. R., N. Nicholls, and A. Ghazi, 1999: CLIVAR/ GCOS/WMO workshop on indices and indicators for climate extremes workshop summary. Weather and Climate Extremes: Changes, Variations and a Perspective from the Insurance Industry, Springer, Dordrecht, 3-7, doi: 10.1007/978-94-015-9265-9_2. [Link]

Li, D., E. Bou-Zeid, M. L. Baeck, S. Jessup, and J. A. Smith, 2013: Modeling land surface processes and heavy rainfall in urban environments: Sensitivity to urban surface representations. J. Hydrometeorol., 14, 1098-1118, doi: 10.1175/jhm-d-12-0154.1. [Link]

Li, F., 2014: Spatial-temporal changes and the causes of extreme precipitation events to the north and south of Qinling Mountain during 1962-2011. Master Thesis, Northwest Normal University, China. (in Chinese)

Li, J. and Q. Zeng, 2000: Significance of the normalized seasonality of wind field and its rationality for characterizing the monsoon. Sci. China Ser. D-Earth Sci., 43, 646-653, doi: 10.1007/BF02879509. [Link]

Li, J. and Q. Zeng, 2002: A unified monsoon index. Geophys. Res. Lett., 29, 115-1-115-4, doi: 10.1029/2001GL013874. [Link]

Li, J., Z. Wu, Z. Jiang, and J. He, 2010: Can Global Warming Strengthen the East Asian Summer Monsoon? J. Clim., 23, 6696-6705, doi: 10.1175/2010JCLI3434.1. [Link]

Li, J., J. Feng, and Y. Li, 2012: A possible cause of decreasing summer rainfall in northeast Australia. Int. J. Climatol., 32, 995-1005, doi: 10.1002/joc.2328. [Link] Li, J., Y. Zhao, and J. Iqbal, 2019: Variation patterns of ex- treme precipitation and relation to ocean-atmospheric climate in Sichuan province China from 1961 to 2017. Theor. Appl. Climatol., 137, 3009-3026, doi: 10.1007/ s00704-019-02792-1. [Link]

Li, S., S. Yang, and X. Liu, 2015a: Spatiotemporal variability of extreme precipitation in north and south of the Qinling-Huaihe region and influencing factors during 1960-2013. Progress in Geography, 34, 354-363, doi: 10.11820/dlkxjz.2015.03.010. [Link]

Li, Y.-G., D. He, J.-M. Hu, and J. Cao, 2015b: Variability of extreme precipitation over Yunnan Province, China 1960-2012. Int. J. Climatol., 35, 245-258, doi: 10.1002/joc.3977. [Link]

Liu, S., S. Huang, Q. Huang, Y. Xie, G. Leng, J. Luan, X. Song, X. Wei, and X. Li, 2017: Identification of the non-stationarity of extreme precipitation events and correlations with large-scale ocean-atmospheric circulation patterns: A case study in the Wei River Basin, China. J. Hydrol., 548, 184-195, doi: 10.1016/j.jhydrol.2017.03.012. [Link]

Lu, F. and H. Lu, 2019: A high-resolution grid dataset of air temperature and precipitation for Qinling-Daba Mountains in central China and its implications for regional climate. Acta Geographica Sinica, 74, 875-888, doi: 10.11821/dlxb201905003. (in Chinese) [Link]

Pathirana, A., H. B. Denekew, W. Veerbeek, C. Zevenbergen, and A. T. Banda, 2014: Impact of urban growthdriven landuse change on microclimate and extreme precipitation - A sensitivity study. Atmos. Res., 138, 59-72, doi: 10.1016/j.atmosres.2013.10.005. [Link]

Peterson, T. C., 2005: Climate Change Indices. WMO Bulletin, 54, 83-86.

Peterson, T. C., C. Folland, G. Gruza, W. Hogg, A. Mokssit, and N. Plummer, 2001: Report on the Activities of the Working Group on Climate Change Detection and Related Rapporteurs 1998-2001, WMO-TD-No. 1071, WCDMP-No. 47, World Meteorological Organization (WMO), Geneve, Switzerland, 143 pp.

Prudhomme, C. and D. W. Reed, 1998: Relationships between extreme daily precipitation and topography in a mountainous region: A case study in Scotland. Int. J. Climatol., 18, 1439-1453, doi: 10.1002/ (SICI) 1097-0088(19981115)18:13<1439::AIDJOC320 $>3.0 . C O ; 2-7$. [Link]

Qi, W., A. Liu, and W. Zhang, 2017: Object-oriented Quantitative Segmentation for China's Three Terrain Grades. Remote Sensing Information, 32, 43-48, doi: 10.3969/j.issn.1000-3177.2017.02.007. (in Chinese) [Link]

Rahmani, V. and J. Harrington, 2019: Assessment of climate change for extreme precipitation indices: A case study from the central United States. Int. J. Climatol., 39, 1013-1025, doi: 10.1002/joc.5858. [Link] 
Ren, Y., 2012: Vegetation index change and its driving force analysis in Daba Mountains. Master Thesis, Northwest University, China. (in Chinese)

Sahoo, S. K., P. P. Ajilesh, K. C. Gouda, and S. Himesh, 2020: Impact of land-use changes on the genesis and evolution of extreme rainfall event: A case study over Uttarakhand, India. Theor. Appl. Climatol., 140, 915926, doi: 10.1007/s00704-020-03129-z. [Link]

Salmi, T., A. Määttä, P. Anttila, T. Ruoho-Airola, and T. Amnell, 2002: Detecting Trends of Annual Values of Atmospheric Pollutants by the Mann-Kendall Test and Sen's Slope Estimates - the Excel Template Application MAKESENS, Publications on Air Quality No. 31, $35 \mathrm{pp}$.

Shao, Y., X. Mu, Y. He, W. Sun, G. Zhao, and P. Gao, 2019: Spatiotemporal variations of extreme precipitation events at multi-time scales in the Qinling-Daba mountains region, China. Quat. Int., 525, 89-102, doi: 10.1016/j.quaint.2019.07.029. [Link]

Sigdel, M. and Y. Ma, 2017: Variability and trends in daily precipitation extremes on the northern and southern slopes of the central Himalaya. Theor. Appl. Climatol., 130, 571-581, doi: 10.1007/s00704-016-1916-5. [Link]

Sun, J. and F. Zhang, 2017: Daily extreme precipitation and trends over China. Sci. China Earth Sci., 60, 21902203, doi: 10.1007/s11430-016-9117-8. [Link]

Sun, W., X. Mu, X. Song, D. Wu, A. Cheng, and B. Qiu, 2016: Changes in extreme temperature and precipitation events in the Loess Plateau (China) during 19602013 under global warming. Atmos. Res., 168, 33-48, doi: 10.1016/j.atmosres.2015.09.001. [Link]

Tang, C., N. Rengers, T. W. J. van Asch, Y. H. Yang, and G. F. Wang, 2011: Triggering conditions and depositional characteristics of a disastrous debris flow event in Zhouqu city, Gansu Province, northwestern China. Nat. Hazards Earth Syst. Sci., 11, 2903-2912, doi: 10.5194/nhess-11-2903-2011. [Link]

Wang, B., Z. Wu, J. Li, J. Liu, C.-P. Chang, Y. Ding, and G. $\mathrm{Wu}, 2008$ : How to Measure the Strength of the East Asian Summer Monsoon. J. Clim., 21, 4449-4463, doi: 10.1175/2008jcli2183.1. [Link]

Wang, J., H.-J. Wang, and Y. Hong, 2016: Comparison of satellite-estimated and model-forecasted rainfall data during a deadly debris-flow event in Zhouqu, Northwest China. Atmos. Ocean. Sci. Lett., 9, 139-145, doi: 10.1080/16742834.2016.1142825. [Link]

Wang, L., Z. Wu, H. He, F. Wang, H. Du, and S. Zong, 2017: Changes in summer extreme precipitation in Northeast Asia and their relationships with the East Asian summer monsoon during 1961-2009. Int. J. Climatol., 37, 25-35, doi: 10.1002/joc.4683. [Link]

Wang, L., S. Chen, W. Zhu, H. Ren, L. Zhang, and L. Zhu, 2021: Spatiotemporal variations of extreme precipita- tion and its potential driving factors in China's NorthSouth Transition Zone during 1960-2017. Atmos. Res., 252, 105429, doi: 10.1016/j.atmosres.2020.105429. [Link]

Wang, X. L., 2008a: Accounting for autocorrelation in detecting mean shifts in climate data series using the penalized maximal t or F test. J. Appl. Meteorol. Climatol., 47, 2423-2444, doi: 10.1175/2008JAMC1741.1. [Link]

Wang, X. L., 2008b: Penalized Maximal $F$ Test for Detecting Undocumented Mean Shift without Trend Change. J. Atmos. Ocean. Technol., 25, 368-384, doi: 10.1175/2007JTECHA982.1. [Link]

Wu, R., 2002: A mid-latitude Asian circulation anomaly pattern in boreal summer and its connection with the Indian and East Asian summer monsoons. Int. J. Climatol., 22, 1879-1895, doi: 10.1002/joc.845. [Link]

$\mathrm{Yu}, \mathrm{M}$. and Y. Liu, 2015: The possible impact of urbanization on a heavy rainfall event in Beijing. J. Geophys. Res., 120, 8132-8143, doi: 10.1002/2015JD023336. [Link]

Zhang, H., C. Wu, W. Chen, and G. Huang, 2019: Effect of urban expansion on summer rainfall in the Pearl River Delta, South China. J. Hydrol., 568, 747-757, doi: 10.1016/j.jhydrol.2018.11.036. [Link]

Zhang, J., X. Shen, and B. Wang, 2015: Changes in precipitation extremes in Southeastern Tibet, China.Quat.Int., 380-381, 49-59, doi: 10.1016/j.quaint.2015.02.009. [Link]

Zhang, J., Y. Jiang, H. Chen, and Z. Wu, 2018a: Doublemode adjustment of Tibetan Plateau heating to the summer circumglobal teleconnection in the Northern Hemisphere. Int. J. Climatol., 38, 663-676, doi: 10.1002/joc.5201. [Link]

Zhang, K., S. Pan, L. Cao, Y. Wang, Y. Zhao, and W. Zhang, 2014a: Spatial distribution and temporal trends in precipitation extremes over the Hengduan Mountains region, China, from 1961 to 2012. Quat. Int., 349, 346-356, doi: 10.1016/j.quaint.2014.04.050. [Link]

Zhang, Q., J. Peng, V. P. Singh, J. Li, and Y. D. Chen, 2014b: Spatio-temporal variations of precipitation in arid and semiarid regions of China: The Yellow River basin as a case study. Glob. Planet. Change, 114, 3849, doi: 10.1016/j.gloplacha.2014.01.005. [Link]

Zhang, Q., Y. Zheng, V. P. Singh, M. Luo, and Z. Xie, 2017: Summer extreme precipitation in eastern China: Mechanisms and impacts. J. Geophys. Res., 122, 27662778, doi: 10.1002/2016JD025913. [Link]

Zhang, W., T. Zhou, L. Zou, L. Zhang, and X. Chen, 2018b: Reduced exposure to extreme precipitation from $0.5^{\circ} \mathrm{C}$ less warming in global land monsoon regions. Nat. Commun., 9, 3153, doi: 10.1038/s41467-018-05633-3. [Link] 
Zhang, X. and M. Liu, 2016: Assessing the Spatial and Temporal Patterns of Seasonal Precipitation Extremes and the Potential Influencing Factors in Dongting Lake Basin, China. Water, 8, 558, doi: 10.3390/w8120558. [Link]

Zhou, X. and W. Lei, 2018: Complex patterns of precipitation and extreme events during 1951-2011 in Sichuan
Basin, Southwestern China. J. Mt. Sci., 15, 340-356, doi: 10.1007/s11629-016-4186-x. [Link]

Zhong, K., F. Zheng, H. Wu, C. Qin, and X. Xu, 2017: Dynamic changes in temperature extremes and their association with atmospheric circulation patterns in the Songhua River Basin, China. Atmos. Res., 190, 77-88, doi: 10.1016/j.atmosres.2017.02.012. [Link] 